\title{
ANNOTATION
}

\section{Fact and Fiction}

Among the minor difficulties of war time, we cannot say " minor horrors," is that of providing comments on current ophthalmological literature, whether in abstract or in annotation. The first number of Vol. XXVI appears after more than two years of a gigantic world upheaval and it is not surprising that difficulties have arisen. We owe it to those contributors who have continued to send us papers that we have been able to appear with regularity each month. The British Journal of Ophthalmology started its career towards the end of the last great war. Some may have thought at the time that it was a risky procedure, but we weathered the storm and we believe that we shall be able to weather the present typhoon. It is with feelings of stedfast hope that we begin yet another volume.

In place of a set discourse on ophthalmological facts we hope we shall be pardoned if we stray into the region of ophthalmology in fiction. This is full of ophthalmological details, from the "irids," which seem to have been a favourite theme among the "Brontë Sisters," to Mr. Squeers's single eye. How many of these ocular details have stuck in one's mind from the mere verbal description it is difficult to say. Every reader of "Treasure Island" remembers Pew, who lost his deadlights by the same broadside that carried away Long John Silver's leg. The picture of the old scamp being knocked down by the rider of a horse has left as vivid a picture on the mind of the writer of this note as the description in the text. Stevenson seems to have been rather fond of introducing blind characters in his works for there is another example in the formidable blind catechist in " Kidnapped."

Another old friend of ours is MacGuffog in "Guy Mannering." In the text he had a "portentous squint of the left eye," but the illustration in the 1860 edition shows him with the squint in his right eye, a fact we only appreciated on re-reading the work recently.

The Reverend Mr. Platitude squinted with both eyes, if we can rely on George Borrow, perhaps he meant to indicate an alternating squint. If we think for a moment on the famous pugilistic accounts in fiction what a wealth of black eyes will rise to the imagination. "Smart chap that cabman, handled his fives well. Waiter, raw beef steak for the gentleman's eye," will occur to every one who has read Pickwick, while other classical fights are those of Tom Brown and Slogger Williams, Lavengro and the Flaming Tinman, Cuff. and Dobbin down to the Smith's last fight in "Rodney Stone." 
Was the obliquity observed in Tristram Shandy in setting up his top due to an ocular cause? And what are we to say of the imaginary foreign body in Widow Wadman's eye? " It did my Uncle Toby's business." Hereditary cases of squint are recorded in Lord Lytton's " Night and Morning," where Mrs. Plimmins, "who had a sad squint," transmitted the defect to each of her three children, causing her aunt to muse upon the mysteriousness of "natur."

Readers can multiply examples of ophthalmology in fiction to their heart's content; we will end these random jottings by asking a simple question. No prize is offered for a correct answer. Which of Commodore Trunnion's eyes was the blind one?

\section{ABSTRACTS}

\section{MISCELLANEOUS}

(1) Klien, Bertha A. (Chicago).-Detachment of the pars ciliaris retinae. A contribution to the diagnosis of malignant intraocular tumours. Arch. of Ophthal., September, 1941.

(1) Klien draws attention to a sign which may be of considerable value in the differential diagnosis between simple and malignant detachment of the retina. The sign consists in detachment of the pars ciliaris retinae and it was present in about 50 per cent. of cases of sarcoma of the choroid and absent in all cases of simple detachment and in cases of Coats disease. It was observed, how ever, in some cases of violent trauma to the eye. The detached pars ciliaris retinae may require careful examination for its discovery, and in some instances a contact lens has to be applied so as to allow of getting well out to the periphery. When seen, it appears as a delicate gray, smoothly rounded, avascular membrane, often showing fine wrinkles and bulging forward. The detachment is of a serous nature, produced by the increased pressure in the subretinal space brought about by the growth which itself may be well behind the equator of the eye.

$$
\text { F. A. W-N. }
$$

(2) Klauder, Joseph V. (Philadelphia) and Vandoren, Eleanor (Washington, D.C.).-Interstitial keratitis. Analysis of five hundred and thirty-two cases with particular reference to standardization of treatment. Arch. of Ophthal., September, 1941.

(2) Klauder and Vandoren's paper is based on an analysis of the records of 532 patients with interstitial keratitis who were 